\title{
Peculiarities of Pre-Synergetic and Synergetic Approaches to the Cognition of Existence
}

\author{
Jury F. Abramova and Olga V. Bondarenko ${ }^{\text {b* }}$ \\ arkutsk State University \\ 3 Karl Marx Str., Irkutsk, 664003, Russia \\ ${ }^{b}$ Irkutsk State Agricultural Academy \\ Pos. Molodezhnyi, Irkutsk oblast, 664038, Russia
}

The peculiarities of pre-synergetic and synergetic approaches to the cognition of existence (complex objects) are studied in the article. The necessity to change theoretical and methodological principles of cognition of existence is proved, Daoism of synergetics and poly-variability of recovery of ontology of complex objects' development processes are inferred.

Keywords: synergetics, ontology, cognition, existence.

Research area: Philosophy.

\section{Introduction}

A new paradigm of existence actualizes not only ontological but "procedural" dimension of cognition. Historicity of cognitionis determined by the nature of knowledge as a cultural phenomenon: human activity is not due to human mentality, but rather the opposite - human mentality is generated by the peculiarities of a human's purposeful activity. In the process of cognition a specific mental activity serves a "mediator" between goal setting and goal achievement. The choice of potential means and forms of action for mastering the reality results from the nature of knowledge as a cultural phenomenon. Due to the fact that cognitive attitude is derived from an effective one an object is specified not as a result or purpose, but as an image and sequence of actions for mastering the reality. Ways of cognition, instrumental paradigms of an object's ontological representations may be different, but they always depend on the type of self-realization of the subjects, acting, one way or the other, with the knowledge, from the options of "practices of working with knowledge".

\section{Statement of the problem}

A gnoseological belief in an indirect manifestation of the "hidden" world in the world of visible things led to "bifocal" model of the cognizable world for a long time: the world of visible things and the world of hidden things. This model played a role of a strong tradition in

(C) Siberian Federal University. All rights reserved

* Corresponding author E-mail address: philosophy@chair.isu.ru 
science. Acknowledgement of fundamentality of variability (Heraclitus axiom) and self-identity (Parmenides axiom) as mutually complementary and distinctive, as well as a peculiar, according to V.I. Arshinov, "lens mindset" resulted in the establishment of a one-to-one correspondence of the two focuses of being - the "hidden" and the "visible" worlds. It suffices to recall the postulate of geometric optics: a lens is an instrument, shaping the image of reality (although the image of hidden things can have a completely different nature and architecture in comparison with its prototype of the visible world) in the form of objects, in which each point of the original corresponds to the point of image with a high degree of accuracy; they present a harmonious correlation of self-identical changes of two focuses of being. Using of the lens as a basic gnoseological model of information transfer from the object analyzed to the subject of cognition resulted in a peculiar "point-wise mapping". The lens immensely intensifies the process of our "edge" awareness of different parts of the object as patterns, which are separate and delineated from each other, and relations between these parts, thereby significantly impeding or even possibly distorting the perception of the whole (Arshinov, Budanov 1999).

However, the quantum mechanics has exposed the narrowness of the description, which would be coherent to an instrumental context of a classical lens order, analysis and synthesis of point-wise elements as well defined parts of an integral image.

"Pre-synergetic" science mainly constructed the models to study the actual being of objects, i.e. qualitative and quantitative characteristics of one level of systems organization (i.e. objects of macro world in classical mechanics, objects of micro world in quantum mechanics, macroand microeconomics, respectively, etc.). In other words, the science this context was a kind of onedimensional.

\section{Discussion}

If a classical science can be considered to be a relevant antique philosophical tradition, then synergetics is a kind of a daoism one. This peculiar feature of synergetics is manifested, firstly, in search for common regularities of the formation process (following the Middle Way), i.e. the birth of a new quality (Dao phenomenon is not constant Dao but they have the same origin) [Waldrop 1993]. Secondly, synergetic objects always appear as entire-systems, i.e. the structures for which the integrity property (the whole is a base of being) is a dominant attribute of their essence (Krylov 1998).

So, if we turn to the content of the seven basic assumptions of classical Chinese "Book of Changes" (in its modern interpretation), Daoism of synergy or synergy of Confucianism can be clearly seen there:

1) the world by itself represents variability and permanence, and, moreover, their immediate unity;

2) this is based on the polarity, going through the entire world; antipodes of this polarity are as much opposed to each other as they gravitate to each other; there is the world movement, the rhythm in their relations;

3) owing to the rhythm what has became and what has not yet occurred come together in one system, according to which the future (as "sprouts" of upcoming events) already exists in the present;

4) both theoretical understanding and practical realization of this are necessary; and if human activity is normalized so that he harmonically fits in his environment;

5) thus, the conflict of the internal and the external is out of the question, they only develop each other as the internal is determined by the external and creates in the external (outer);

6) herewith a person pays sufficient attention to both him/herself and the surrounding 
community, and, satisfied with his position, finds the possibility of higher forms of creativity: creativity of the good but not of the performing any of the copybook morality rules;

7) thus, owing to the sustained unity of abstraction and concreteness the full flexibility is achieved (Confucius 1999).

It can be said that the ancient principle of harmony of the world as balance, "ying-yang" alternation, their presence in each other imply that throbbing equilibrium or disequilibrium. It seems to reborn anew in synergetic laws of selforganization of the complex, finding the rigorous mathematical form appropriate to a modern stage of civilization development.

Adoption of a synergetic paradigm means not only the rejection of idealization of an absolutely isolated system that neither interacts with the outside world nor has a feedback loop, but the recognition of the two-dimensionality (and even multi-dimensionality) of modern science in the study of the processes of the formation of the complex (dissipative systems). Consequently, for a holistic description of the process of selforganization, i.e. the process of establishing the new (but the old value - an "old" macroobject seems to disappear at the bifurcation point), the description of the dynamics model at the microscopic level (chaos) is necessary to be supplemented by the description of macrodynamics (order).

It should be kept in mind that chaos as an internal property of a nonlinear dynamic system occurs almost always and nearly everywhere and not only in complex systems. The fact is that chaos dwells on "boarders" of spatiotemporal scales of our perception of reality as what has already occurred.

Shifting the study emphases from being to becoming leads not only to a radical rethinking of the role of chaos in the universe, but also requires a new approach to the cognition of the complex, in which a cooperative relationship of sensorial, mental, rational, social and natural as the subsystems involved in the processes of self-organization re-opens. Their set actually realizes our presence in this changing world, formation of our being in it. In its turn, this leads to the notion of a new instrumentally generated paradigm of scientific knowledge - to the image of "epistemological" (Hacken's) laser, which is fundamentally different from the "lens-type thinking".

Using the image of laser as an instrumentally generated paradigm of modern scientific cognition is not accidental. It is determined by several factors:

firstly, the "epistemological" laser not only embodies a new model of an operational side of cognitive activity as it seems to spotlight the interference pattern with its coherent radiation, the pattern being the whole (hologram), which corresponds with the ontological object not point wise as in a lens but in a much more complex way, giving information in its nonlocal dynamically distributed form, causing poly-variance of recovering the ontologies according to the data of cognitive-measuring circuits;

secondly, the image of the laser serves the basis for presentation and initiation of selforganization processes in the environments totally different in their "substrate" structure, but similar in their behavior near the points of instability (Arshinov, Budanov 1999);

thirdly, it is highly significant that the laser itself is a model of synergetic objects, i.e. such systems for which order and equilibrium of macro-manifestations are caused by chaotic dynamics, non-equilibrium and phase transitions on the micro level.

It should be specially emphasized that according to the synergetic interpretation of the development (not as the formed being but as a forming one) it is the disequilibrium which is a 
prerequisite for self-organization (the formation of new, relatively stable structures of the system and new relations of the system with the environment). Disequilibrium leads to the loss of stability, i.e. the loss of ability of a dynamic system to support the immutability of existing parameters and the existing mode of operation (to keep movement along the planned trajectory) under the influence of environmental factors.

The study of an objective-and-universal relationship of chaos and order has led to the discovery of a fundamentally new way of the open non-equilibrium systems' motion (all real natural and social systems are practically of such a kind) to the state of stability. Therefore, designing the dissipative systems models, we have to abandon the traditional interpretation of dynamics (evolution) as a transition from one ordered structure to another, i.e. as a transition from one order to another order but of a more or less complex type. It is also necessary to remove the opposition of chaos and order, legitimize the instability as a source of the stable structures formation; to move from a static ideal of the description completeness to a dynamic ideal of integrity. In other words, in accordance with the "laser" paradigm a measure of uncertainty should be a focus of the dissipative system research while preserving the integrity as a dominant attribute of an ordered structure.

Nonlinearity, once meant to be the presence of several qualitatively different solutions of a mathematical equation, has acquired a fundamental significance, meaning the disproportion (in material-and-energetic and / or informational dimension) of results, efforts made, violation of the superposition principle. Moreover, it has become a methodological principle of describing the dynamics of the complex (dissipative systems), the study of which is impossible without building a hierarchy of simplified models.
Basing on the fact that the redundancy of mathematical models (i.e. the presence of many degrees of freedom which do not really affect the observed dynamics of the system) allows to identify the parameters oforder, those key variables that determine all other degrees of the system's freedom, we can build a hierarchy of simplified models. The theory of the order parameters, which received a rigorous mathematical proof and experimental confirmation, is a methodological basis of the transition from an infinite set of independent random variables to a finite (small) number of variables (Knyazeva, Kurdiumov 2005). Therefore the methodological principle of coagulation complex is the following: attractors of dissipative structures' evolution are described much simpler than a tangle of paths of transients processes to them, fix an operational side of viewing the reality.

The reduction of the mechanical trajectory with the randomly chosen initial data to the research of a dynamical system's behavior on the attractor is determined by the so-called holistic view on the system, evolution of which is characterized by the "quantum" spectrum of ways of development. Because of this the most difficult theoretic-and-methodological problem is the development of various scenarios of the system's possible dynamics. Mathematically, "wandering on the field of the possible" and choosing one of the evolution paths is described as a set of initial data, which lead to the emergence of domains of attraction of various attractors. It is especially important in the mathematical model to take into account the fact that the dissipative system's structures are not stark formations, but localized processes which move, rearrange, fade (just like in a laser), etc.

"Strange attractors" have become an integral part of the dissipative systems' theory. According to Ruelle and Takens, the authors of this concept, "strange attractors" consist of such solutions of 
difference equations, which do not fill any area but form a complex "holey" topology. Thus, they are fractals. It is their fractality that determines the properties of this structure. Experiments show that a fractal dimension is closely connected with the essential parameters of the system, defining a collective (coherent) character of its dynamics. In fact, in the phase space of many natural and social facilities there are places, in which a chance or a factor with no value in any other situation can turn out to be decisive and not only affect the system's "destiny" but also abruptly convert it to another point in the phase space. It is clear that this greatly increases the number of variants and the degree of uncertainty (on the ontological level) and means that the system's behavior is accurately determined by only a few variables, all the rest is insignificant in this case (Mainzer 2008).

Applying the "epistemological" laser paradigm and the "strange attractors" strategy to building the hierarchy of simplified models of social or natural phenomena cannot do without the concept of bifurcation. All real (complex) systems contain subsystems that continually fluctuate. Sometimes separate fluctuation or a combination of fluctuations can be (as a result of a positive feedback) so strong that the organization, which existed before, does not survive and is destroyed. At this critical point - the point of bifurcation - it is fundamentally impossible to predict the direction of further development, and namely whether the system's state will be chaotic or move to a new, more differentiated and higher level of order or organization. Essentially bifurcation is a mathematical way of the "transition from quantitative changes to qualitative ones", of a structural stability, i.e. a topological equivalence of the set of the dynamic systems' trajectories, in which the loss of stability and the transition through a chaotic stage to a different stable state are carried out at the bifurcation point.

\section{Conclusion}

However, currently available mathematical methods and techniques of the real systems' behavior reconstruction are sufficient predominantly for the qualitative analysis of the description of evolutionary processes in open dissipative systems, in which the exchange of material and energy with the "outside world" takes place. Nevertheless, the use of the "laser" paradigm results in a principal possibility of solving the problem of sensitivity of complex objects' "trajectories" to the initial data and their diversity in the phase space, and the problem of the redundancy of mathematical models (availability of multiple degrees of freedom which are almost "not involved" in actually observed dynamics).

Thus, the multidimensionality of cognitive models of nonlinear (dissipative) systems, a qualitative change of initial principles of building "synergetic" models, requiring new methodological techniques (coagulation of the "complex", building a hierarchy of simplified models, development of the system's evolution "scenarios, etc.) and a new logicaland-mathematical apparatus (the theory of mathematical categories, fractal geometry, etc.), lead to the poly-variance of the recovery of the ontology of the development processes of the complex.

\section{References}

1. Arshinov V. I., Budanov V.G. (1999). Sinergetics of observation supervision as a cognitive process. Filosofiia, nauka, tsivilizatsiia, p. 244, 249-250.

2. Confucius. Wisdom lessons: Works. Moscow, 1999. P. 596-597. 
3. Kniazeva E.N., Kurdiumov S.P. The bases of synergetics. Synergetic Outlook. Moscow, 2005. P. 57-58.

4. Krylov J.K. Entirelogycs and synergetics. Synergetics and methods of science. St. Petersburg., 1998. P. 79-80.

5. Mainzer K. Thinking in Complexity. New York, 2008.

6. Chinese classics' works. Vol. 4. Moscow-Tokyo, 1967.

7. Waldrop M. The emerging science at the edge of order and chaos. New York, 1993.

\title{
Особенности «до-синергетического»
}

\section{и синергетического подходов}

к познанию бытия

\author{
Ю.Ф. Абрамов ${ }^{\mathbf{a}}$ О.В. Бондаренко \\ ${ }^{a}$ Иркутский государственный университет \\ Россия, 664003, Иркутск, ул. К. Маркса, 3 \\ Иркутская государственная сельскохозяйственная академия \\ Россия, 664038, Иркутская область, пос. Молодежный
}

Рассмотрены особенности до-синергетического и синергетического подходов к познанию бытия (сложных объектов). Обоснована необходимость изменения теоретикометодологических принципов познания бытия, сделан вывод о даоистичности синергетики, о поливариантности восстановления онтологии процессов развития сложных объектов.

Ключевые слова: синергетика, онтология, познание, бытие.

Научная специальность: 09.00.00 - философские науки. 